\title{
Persistence and Compliance Among U.S. Patients Receiving Pazopanib or Sunitinib as First-Line Therapy for Advanced Renal Cell Carcinoma: A Retrospective Claims Analysis
}

\author{
Stacey A. DaCosta Byfield, PhD, MPH; Jeffrey T. McPheeters, BA; Tanya M. Burton, PhD; \\ Saurabh P. Nagar, BPharm, MS; and Michelle D. Hackshaw, BScPharm, MSHS, PhD
}

\begin{abstract}
BACKGROUND: For first-line therapy options for advanced renal cell carcinoma (RCC), clinical trials have demonstrated similar efficacy for pazopanib and sunitinib as well as differing side-effect profiles, which may affect patient persistence in self-administration of these oral medications. However, the treatment patterns of each drug in real-world clinical practice, as opposed to the controlled environment of a trial, have not been directly compared.
\end{abstract}

OBJECTIVE: To compare persistence and compliance (adherence) with pazopanib versus sunitinib in a real-world setting.

METHODS: This was a retrospective claims analysis using 2 databases: Optum Research Database and Impact National Benchmark Database. Eligible patients included adult patients (aged $\geq 18$ years) with $\geq 2$ RCC diagnoses and evidence of first-line therapy with $\geq 1$ subsequent pharmacy claim for pazopanib or sunitinib between October 2009 and July 2012. The date of the first pazopanib or sunitinib claim was defined as the index date. Additional requirements included continuous enrollment in the health plan for 2 months prior (baseline period) through 6 months after (follow-up period) the index date and no cancers other than those associated with RCC. Propensity score matching was used to minimize selection bias. Persistence with the index drug was compared using days to discontinuation, estimated level of persistence (ELPT) at 180 days, and proportion of days covered (PDC). PDC was defined by dividing the number of days covered with the index drug by the number of follow-up days. Compliance was estimated using medication possession ratio (MPR). For matched cohort pairs with $>1$ fill, MPR was defined by dividing the number of days covered with the index drug by the number of days between the first and last index medication fill.

RESULTS: We identified 84 matched pairs among 97 patients prescribed pazopanib and 349 prescribed sunitinib. Among the matched population, mean comorbidity index score was $5.8(95 \% \mathrm{Cl}=1.8-6.0)$ for pazopanib, and $6.1(95 \% \mathrm{Cl}=1.8-6.0)$ for sunitinib $(P=0.133)$. Evidence of any radiation therapy during the baseline period was significantly higher among the sunitinib cohort prior to matching ( $9 \%$ vs. $18 \%, P=0.043$ ), and evidence of surgery was higher in the pazopanib cohort after matching (12\% vs. $7 \%$, $P=0.046)$. Cohorts were balanced according to demographic and clinical characteristics with mean (SD) age of $63.0(9.0)$ years and $77.4 \%$ male. During the 6-month period after drug initiation, there was no significant difference $(P>0.05)$ by drug cohort in the duration of index drug therapy or the percentage of patients who discontinued their index drugs. The mean (SD) time to discontinuation was 133.4 (62.8) days and 139.9 (55.6) days among the matched pazopanib and sunitinib cohorts, respectively $(P=0.445)$. In both cohorts, more than $40 \%$ of patients discontinued their index drugs (46.4\% pazopanib and $44.1 \%$ sunitinib, $P=0.732$ ). In addition, there was no significant difference by drug cohort in the ELPT at any time examined between 30 and 180 days after initiation of therapy.

PDC with the index drug during the fixed 6-month follow-up was also examined. Although the mean PDC was significantly higher among the sunitinib cohort ( 0.77 vs. 0.68 for pazopanib, $P=0.037$ ), there was no difference by cohort in the percentage of patients with high PDC (defined as $\geq \mathbf{8 0} \%$ ): $\mathbf{5 2 . 4 \%}$ versus $\mathbf{5 6 . 0 \%}$ for pazopanib and sunitinib, respectively $(P=0.622)$. Mean MPR among matched pairs with at least 2 fills for the index drug was significantly higher among the sunitinib cohort, although there was no difference by cohort in the percentage of patients with high MPR (defined as $\geq 80 \%$ ): $81.4 \%$ versus $93.2 \%$ for pazopanib and sunitinib, respectively $(P>0.071)$.

CONCLUSIONS: In the first 6 months of treatment, persistence and compliance to pazopanib and sunitinib were similar. Future studies are needed, including those assessing larger cohorts and longer follow-up periods.

J Manag Care Spec Pharm. 2015;21(6):515-22

Copyright $\odot 2015$, Academy of Managed Care Pharmacy. All rights reserved.

\section{What is already known about this subject}

For first-line therapy for advanced renal cell carcinoma (RCC), clinical trials have demonstrated similar efficacy and safety for pazopanib and sunitinib.

One analysis of real-world data demonstrated that more than one-half of advanced RCC patients were on pazopanib for almost 4 months and were persistent and compliant, but the study only assessed pazopanib

\section{What this study adds}

This study directly compared persistence and compliance among patients who receive pazopanib versus sunitinib as first-line therapy for RCC, utilizing health care claims data.

Results of this real-world assessment showed no significant differences between the drugs in mean days to discontinuation or estimated level of persistence over the first 6 months of treatment. The percentage of patients with high persistence and compliance rates did not significantly differ between those being treated with pazopanib versus sunitinib. 
I n the United States, kidney cancer accounts for 4\% of all cancers; in 2015, a total of 61,560 new cases and 14,080 deaths from kidney cancer are expected. ${ }^{1}$ Approximately $90 \%$ of kidney cancers are diagnosed as renal cell carcinoma (RCC). ${ }^{2}$ The average age of patients at diagnosis is 64 years and most are asymptomatic until the cancer is at an advanced or metastatic stage. ${ }^{3,4}$ In contrast to the treatment course for other neoplasms, chemotherapy has no established role in the management of advanced RCC, and the prognosis is poor, with overall median survival of less than 1 year and a 5-year survival rate of approximately 12\%.5,6 Standard initial therapy postsurgery has traditionally been cytokine therapy (interleukin [IL]-2 and/or interferon [IFN]- $\alpha$ ), yet these therapies have toxic effects and offer only limited benefit to select patients. ${ }^{7,8}$

Advances in research for RCC treatments have led to the development of compounds that inhibit the vascular endothelial growth factor (VEGF) pathway. ${ }^{9-11}$ The VEGF inhibitors include sorafenib, sunitinib, pazopanib, axitinib, tivozanib, and the anti-VEGF monoclonal antibody bevacizumab.9-11 In the United States, pazopanib (VOTRIENT, GlaxoSmithKline) ${ }^{12}$ and sunitinib (SUTENT, Pfizer) ${ }^{13}$ are approved by the U.S. Food and Drug Administration and are among the choices for first-line treatment of advanced RCC based on demonstrated improvement in progression-free survival (PFS). ${ }^{14}$

Pazopanib is an oral, once-daily therapy and was approved in 2009. ${ }^{12}$ The efficacy and safety of pazopanib has been demonstrated in a randomized, double-blind, placebo-controlled, phase III trial. ${ }^{15}$ In a treatment-naïve group, median PFS was 11.1 months with pazopanib versus 2.8 months with placebo (hazard ratio $[\mathrm{HR}]=0.40 ; 95 \%$ confidence interval $[\mathrm{CI}]=0.27$ $0.60 ; P<0.0001$ ). In a cytokine-pretreated group, PFS was 7.4 versus 4.2 months, with pazopanib versus placebo, respectively $(\mathrm{HR}=0.54 ; 95 \% \mathrm{CI}=0.35-0.84 ; \mathrm{P}<0.001)$.

Sunitinib is an oral once-daily therapy dosed on a 6 -week schedule (4 weeks on/2 weeks off) and was approved in $2007 .{ }^{13}$ In the phase III study of treatment-naive patients that demonstrated the efficacy of sunitinib, PFS was significantly longer with sunitinib versus IFN-a (11 months vs. 5 months, $\mathrm{HR}=0.42 ; 95 \% \mathrm{CI}=0.32-0.54 ; \mathrm{P}<0.000){ }^{16}$

In a recent head-to-head phase III study comparing efficacy of pazopanib versus sunitinib, pazopanib was demonstrated as being noninferior to sunitinib as indicated by a PFS HR of 1.047 (95\% CI =0.8982-1.2195), meeting the predefined noninferiority margin $(<1.25) \cdot{ }^{17}$ However, although efficacy has been shown to be similar between the 2 drugs, the observed sideeffect profiles were different-which could influence persistence and compliance and, thus, drug effectiveness-outside of the controlled clinical trial setting, particularly as these drugs are dispensed for home oral administration. Real-world data on treatment and utilization patterns (i.e., persistence and compliance) are valuable considerations that may influence treatment choice and clinical outcomes. Thus, using health care claims data, we assessed and compared persistence and compliance (adherence) among patients who received first-line pazopanib versus sunitinib in a real-world clinical practice setting. We expected no difference in persistence and compliance between patients initiating therapy with pazopanib versus patients initiating therapy with sunitinib.

\section{Methods}

\section{Data Sources}

This comparative study employed a retrospective, observational, cohort design to analyze medical data, pharmacy data, and enrollment information between August 1, 2009 , and December 31, 2012, from 2 large U.S. health care claims databases: Optum Research Database (ORD) and IMPACT National Benchmarking Database (IMPACT). ${ }^{18,19}$ Data were available for individuals covered through commercial and Medicare Advantage insurance. Information available in both databases is representative of the geographic diversity across the U.S. population. The medical claims include International Classification of Diseases, Ninth Revision, Clinical Modification (ICD-9-CM) diagnosis and procedure codes. Outpatient pharmacy claims include National Drug Code (NDC) numbers for medications, including fill date, quantity dispensed, dose, and number of days' supply.

\section{Study Sample Selection}

The study population included health plan enrollees with advanced RCC with evidence of pazopanib or sunitinib use as first-line therapy. Patients must have had evidence of firstline (index) therapy defined by at least 1 pharmacy claim for pazopanib (NDC: 00173-0804-09) or sunitinib (NDC: 00069-0550-38, 00069-0550-30, 00069-0770-38, 000690770-30, 00069-0980-38, 00069-0980-30, 54569-5983-00, 54569-5982-00) between October 1, 2009, and July 1, 2012. The date of the first pazopanib or sunitinib claim was defined as the index date. Patients were required to be continuously enrolled in their health plans for 2 months prior to the index date (baseline period) and 6 months after the index date (follow-up period). The timeline was consistent with a previous similar study by our group regarding treatment patterns of pazopanib, as well as clinical trials that demonstrated differences in adverse events that affected health-related quality of life within 6 months of initiating either pazopanib or sunitinib. ${ }^{15,17,20}$ Study patients were also required to be aged $\geq 18$ years with at least 2 claims with a primary diagnosis code of RCC (ICD-9-CM 189.0, 189.1), at least 30 days apart, with at least 1 of the diagnosis claims during the baseline period. Patients were excluded from analysis if they had any claims for immunomodulator or molecular-targeted therapy during the baseline period or had claims for both pazopanib and sunitinib on the index date. Finally, patients were excluded from analysis if they had claims for any other cancers not associated with common RCC metastatic sites (i.e., lung ICD-9-CM 162. xx, bone 170.xx, brain 191.xx, liver 155.xx). 
Patients were assigned to one of the following study cohorts based on the index therapy: (a) pazopanib cohort: patients who received pazopanib monotherapy on the index date or (b) sunitinib cohort: patients who received sunitinib monotherapy on the index date.

\section{Study Measures}

Patient Characteristics. Baseline patient demographic and clinical characteristics were described. Patient demographic data included index year; age; age groups ( $<55$ years, $55-64$ years, or 65+ years); gender; insurance type (commercial or Medicare Advantage); and U.S. Census-designated geographic region (Northeast, Midwest, South, West, or Other). Clinical characteristics included baseline Quan-Charlson comorbidity score ${ }^{21}$ selected comorbidities commonly associated with RCC (i.e., hypertension [ICD-9-CM 401.xx-404.xx], kidney abnormalities [e.g., horseshoe kidney, ICD-9-CM 753.3], polycystic kidney disease [ICD-9-CM 753.1x], and Von Hippel-Lindau disease [ICD-9-CM 759.6]); and RCC-related radiation therapy or surgery during the 2-month baseline period.

Persistence. Persistence was described by 3 measures: time to discontinuation, estimated level of persistence, and proportion of days covered.

Time to discontinuation. Persistence with the index therapy was measured as the number of days from index date to index therapy discontinuation date or end of the 6-month follow-up period, whichever came first. The discontinuation date was defined as the end date of days covered for the last fill prior to a gap of at least 30 days in subsequent prescription fills. For pazopanib, which is dosed once daily continuously, the end date of days covered was the run-out date of the last fill prior to the 30-day gap in prescription fills. Given the sunitinib dosing schedule of 4 weeks on $/ 2$ weeks off, the end date of days covered for sunitinib was the run-out date +14 days if patients had a claim or group of claims with gaps 7 or less days, with a combined days' supply of at least 28 days. This 14-day compliant gap period was not added to the run-out date of claims/ claim clusters where the days' supply was less than 28 days, since days' supply of less than 28 days is not compliant for the "on drug" period for sunitinib.

Estimated level of persistence. The estimated level of persistence (ELPT) is calculated as the percentage of patients remaining on therapy (indicated by refills obtained at the subsequent fill date) at a given time. ${ }^{22}$ The percentage of patients remaining on index therapy at $30,60,90,120$, and 180 days during the 6-month follow-up period was assessed.

Proportion of days covered. The proportion of days covered (PDC) was calculated by dividing the number of days covered for which medication was available by the study follow-up period (184 days). ${ }^{22,23}$ PDC for sunitinib was adjusted for the 4 weeks on/2 weeks off dosing schedule for sunitinib; that is, the 14-day off period for applicable sunitinib fills was included in the number of "days covered." Perfect persistence was defined as 1 ; less than full persistence was defined $\leq 1$. High persistence was defined as $\geq 80 \%$.

Compliance. Compliance with the index therapy was measured using medication possession ratio (MPR), which was defined as the number of days supplied/covered of index medication for all but the last fill in the observation period, divided by number of days between the first and last refill. ${ }^{22}$ For sunitinib, days covered included the 14-day off period for applicable sunitinib fills. High compliance was defined as $\geq 80 \%$. Patients were required to have at least 2 fills. Perfect compliance was defined as 1 ; less than full compliance was defined as $\leq 1$.

\section{Data Analysis}

Propensity Score Matching. Propensity score matching was used to create matched cohorts and to minimize observable selection bias. ${ }^{24}$ Propensity scores were estimated by an unconditional logistic regression analysis incorporating potential predictors of assignment to pazopanib therapy.

Descriptive statistics of patients' prematch demographic and clinical characteristics were examined to determine the selection of matched characteristics. Covariates for the logistic regression model included index year, age group, sex, health plan region, insurance type, baseline Quan-Charlson comorbidity score, evidence of RCC-related surgery in baseline period, and source database (ORD or IMPACT).

Patients were matched in a 1:1 ratio using greedy matching, which is frequently used in observational studies where cases are matched to controls based upon decisions designed to maximize exact matches. ${ }^{25}$ The success of matching was evaluated by comparisons of characteristics included in the propensity score model. Unmatched patients were excluded from the matched sample analysis.

Statistical Analyses. Baseline demographic and clinical characteristics, treatment variables, and persistence and compliance measures were analyzed descriptively for the matched cohorts. Frequencies and proportions were provided for categorical variables, and means and standard deviations (SDs) were provided for continuous variables. Differences in continuous measurements were evaluated with t-tests (paired t-tests when matched), and differences in categorical measures were evaluated with chi-square tests (unmatched) and McNemar tests (matched); where appropriate, exact tests were used. The persistence measure ELPT by cohort was compared using persistence curves and the stratified log-rank test.

\section{Results}

\section{Patient Characteristics}

Of all enrollees in the ORD $(\mathrm{N}=21,873,481)$ and IMPACT $(\mathrm{N}=2,305,607)$ databases between October 1, 2009, and 
Persistence and Compliance Among U.S. Patients Receiving Pazopanib or Sunitinib as

First-Line Therapy for Advanced Renal Cell Carcinoma: A Retrospective Claims Analysis

\section{FIGURE 1 Selection of Study Population}

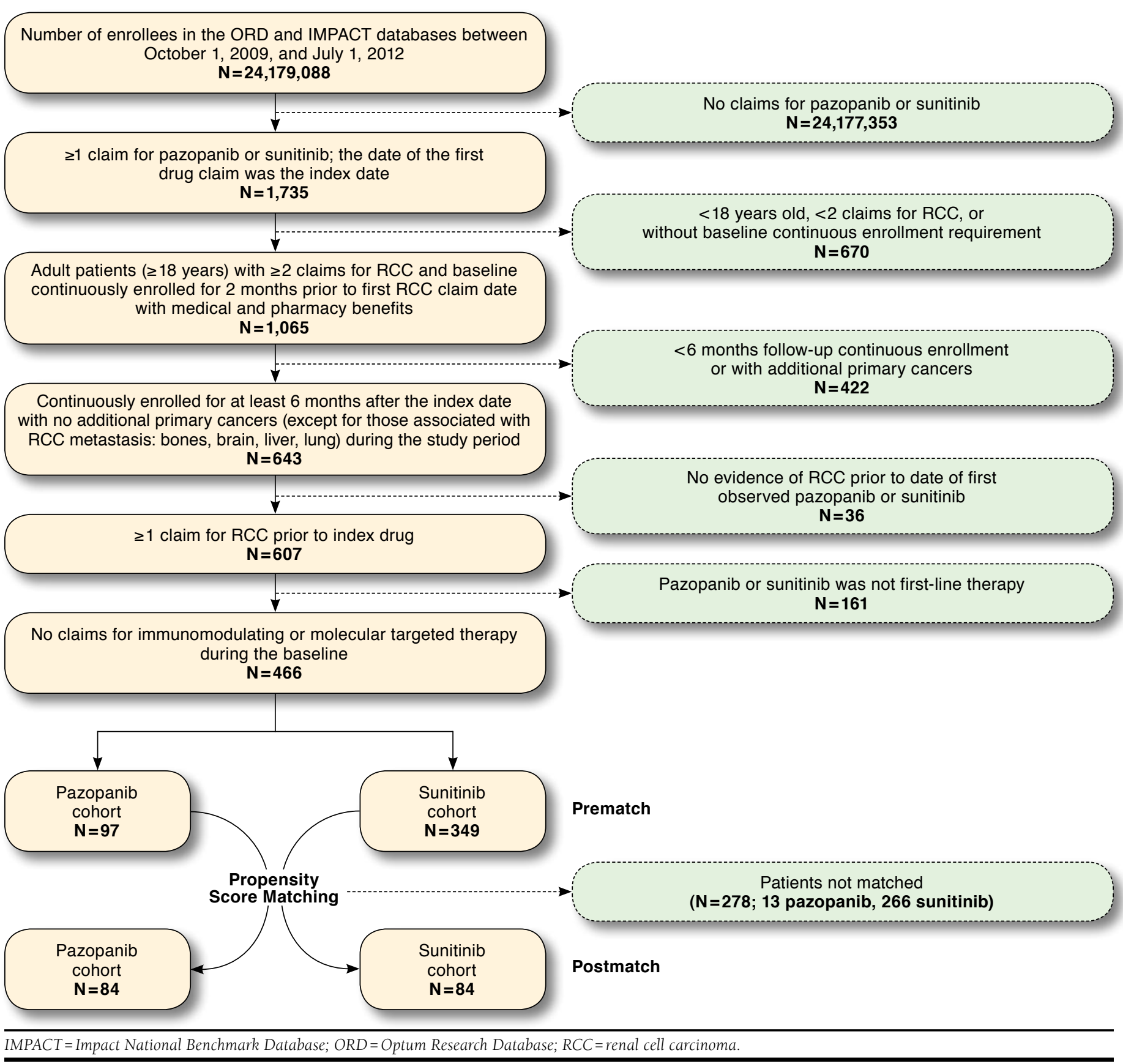

July 1, 2012, 446 patients met the study selection criteria (Figure 1). In total, 97 and 349 patients initiated firstline therapy, with pazopanib or sunitinib, respectively. Propensity score matching resulted in a final study sample size of 84 matched pairs.

Patient baseline characteristics prior to and after matching were not significantly different by drug cohort (Table 1), with the exception of any radiation therapy during baseline (9.3\% vs. $17.8 \%$ in the pazopanib and sunitinib prematched cohorts, respectively; $P=0.043$ ) and the percentage of patients with an index date during the 3-month period between October and December 2009 (3.1\% vs. 15.8\%, $P=0.001$ prematched and $3.6 \%$ vs. $14.3 \%, P=0.035$ matched, pazopanib and sunitinib cohorts, respectively). Among the matched population, the 
Persistence and Compliance Among U.S. Patients Receiving Pazopanib or Sunitinib as

First-Line Therapy for Advanced Renal Cell Carcinoma: A Retrospective Claims Analysis

TABLE 1 Patient Baseline Demographics and Clinical Characteristics ${ }^{a}$

\begin{tabular}{|c|c|c|c|c|c|c|}
\hline & \multicolumn{3}{|c|}{ Prematched } & \multicolumn{3}{|c|}{ Postmatched } \\
\hline & \multirow{2}{*}{$\begin{array}{c}\text { Pazopanib } \\
(\mathrm{N}=97)\end{array}$} & \multirow{2}{*}{$\begin{array}{l}\text { Sunitinib } \\
(\mathrm{N}=349)\end{array}$} & \multirow{2}{*}{$\begin{array}{c}P \\
\text { Value }\end{array}$} & \multirow{2}{*}{$\begin{array}{c}\text { Pazopanib } \\
(\mathrm{N}=84)\end{array}$} & \multirow{2}{*}{$\begin{array}{c}\text { Sunitinib } \\
(\mathrm{N}=84)\end{array}$} & \multirow{2}{*}{$\begin{array}{c}P \\
\text { Value }\end{array}$} \\
\hline & & & & & & \\
\hline Age, mean (SD [median]) & $62.3(9.0[62.0])$ & $62.4(9.9[62.0])$ & 0.957 & $63.9(8.9[63.0])$ & $63.4(9.0[61.5])$ & 0.592 \\
\hline Male, $\mathrm{n}(\%)$ & $75 \quad(77.3)$ & $(69.3)$ & 0.125 & $64 \quad(76.2)$ & $\begin{array}{ll}66 & (78.6) \\
\end{array}$ & 0.727 \\
\hline \multicolumn{7}{|l|}{ Insurance type, n (\%) } \\
\hline Commercial & $71 \quad(73.2)$ & $272 \quad(77.9)$ & 0.327 & $(73.8)$ & $(73.8)$ & 1.000 \\
\hline Medicare Advantage & $26 \quad(26.8)$ & $(22.1)$ & 0.327 & $(26.2)$ & $(26.2)$ & 1.000 \\
\hline \multicolumn{7}{|l|}{ Geographic region, $\mathrm{n}(\%)$} \\
\hline Northeast & $(21.7)$ & $80 \quad(22.9)$ & 0.891 & $(22.6)$ & $(19.1)$ & 0.508 \\
\hline Midwest & $23 \quad(23.7)$ & $(27.8)$ & 0.518 & $(23.6)$ & $(23.8)$ & 1.000 \\
\hline South & $40 \quad(41.2)$ & $(35.2)$ & 0.286 & $(41.7)$ & $(44.1)$ & 0.688 \\
\hline West & $(13.4)$ & $(13.2)$ & 1.000 & $11 \quad(13.1)$ & $(10.7)$ & 0.688 \\
\hline Other & $(0.0)$ & $(0.9)$ & 1.000 & $(0.0)$ & $(2.4)$ & - \\
\hline \multicolumn{7}{|l|}{ Index year, n (\%) } \\
\hline October-December 2009b,c & $(3.1)$ & (15.8) & 0.001 & (3.6) & $(14.3)$ & 0.035 \\
\hline January-December 2010 & $36 \quad(37.1)$ & $(33.2)$ & 0.476 & $34 \quad(40.5)$ & (33.3) & 0.238 \\
\hline January-December 2011 & $(32.0)$ & $(33.0)$ & 0.854 & $(33.3)$ & $(31.0)$ & 0.688 \\
\hline January-June $2012^{\mathrm{b}}$ & $(27.8)$ & $(18.1)$ & 0.034 & $19 \quad(22.6)$ & $(21.4)$ & 1.000 \\
\hline \multicolumn{7}{|l|}{ Selected comorbidities, n (\%) } \\
\hline Hypertension & $49 \quad(50.5)$ & $181 \quad(51.9)$ & 0.814 & $44 \quad(52.4)$ & $(45.2)$ & 0.396 \\
\hline Horseshoe kidney & $(0.0)$ & $(0.6)$ & 1.000 & $(0.0)$ & $(1.2)$ & - \\
\hline Polycystic kidney disease & $(2.1)$ & $(1.7)$ & 0.687 & $(1.2)$ & $(1.2)$ & 1.000 \\
\hline Von Hippel-Lindau disease & $(0.0)$ & $(0.0)$ & - & $(0.0)$ & $(0.0)$ & - \\
\hline Any radiation therapy, $\mathbf{n}(\%)^{b}$ & $(9.3)$ & $(17.8)$ & 0.043 & $(10.7)$ & $(17.9)$ & 0.146 \\
\hline RCC-related surgery, n (\%) ${ }^{b, c}$ & $13 \quad(13.0)$ & $50 \quad(14.0)$ & 0.817 & $(11.9)$ & $(7.1)$ & 0.125 \\
\hline $\begin{array}{l}\text { Baseline Quan-Charlson comorbidity score, } \\
\text { mean (SD [median]) }\end{array}$ & $5.79(1.91[6.00])$ & $5.86(2.08[6.00])$ & 0.770 & $5.81(1.82[6.00])$ & $6.12(1.83[6.00])$ & 0.133 \\
\hline \multicolumn{7}{|c|}{$\begin{array}{l}\text { aFor the prematched population, we used Pearson's chi-square to test differences in categorical data and the t-test for continuous data. If cell sizes were below } 5 \text {, we used } \\
\text { Fisher's exact test for categorical data testing. For the matched population, we used the McNemar test to test differences in categorical data and the paired t-test for con- } \\
\text { tinuous data. If discordant pairs were }<20 \text {, we used the exact McNemar test for categorical data testing. } \\
{ }^{b} P<0.05 \text { for comparison between prematched pazopanib vs. sunitinib. } \\
{ }^{c} P<0.05 \text { for comparison between postmatched pazopanib vs. sunitinib. } \\
R C C=\text { renal cell carcinoma; } S D=\text { standard deviation. }\end{array}$} \\
\hline
\end{tabular}

mean (SD) age was 63.0 (9.0) years; most were commercially insured (73.8\%); and $77.4 \%$ were male.

\section{Persistence and Compliance}

Measures of persistence and compliance are shown in Table 2. No significant difference $(P>0.05)$ was observed in the duration of index drug therapy or percentage of patients who discontinued. Mean (SD) time to discontinuation was 133.4 (62.8) days and 139.9 (55.6) days among pazopanib and sunitinib cohorts, respectively.

More than $50 \%$ of patients continued on their index drug through the 6-month follow-up period, and no significant difference was found in the discontinuation rates between cohorts (46.4\% pazopanib and $44.1 \%$ sunitinib). In addition, no significant difference by cohort was found in the ELPT between 30 and 180 days after initiation of therapy. Figure 2 shows the persistency curves of time to discontinuation, with no significant difference by drug cohort.
PDC (persistence) and MPR (compliance) measures were generally similar between cohorts. Although the mean PDC was significantly higher among the sunitinib cohort versus the pazopanib cohort ( 0.77 vs. $0.68, P=0.037)$, there was no difference in the percentage of patients with high ( $\geq 80 \%)$ PDC $(52.4 \%$ vs. $56.0 \%$ in pazopanib vs. sunitinib cohorts, respectively). The mean MPR was significantly lower with pazopanib versus sunitinib ( 0.90 vs. 0.95 , respectively, $P=0.008$ ), but the percentage of patients with high $(\geq 80 \%)$ MPR was not significantly different (pazopanib $=81.4 \%$, sunitinib $=93.2 \%, P=0.118$ ).

\section{Discussion}

As compared with clinical trial results, the effectiveness of oral anticancer drugs in clinical practice is adversely affected by patient noncompliance. ${ }^{26,27}$ Studies have consistently demonstrated lower compliance in real-world practice than in clinical trials. ${ }^{28-30}$ Although a clinical trial demonstrated similar efficacy and differing safety profiles of pazopanib and sunitinib as 
Persistence and Compliance Among U.S. Patients Receiving Pazopanib or Sunitinib as

First-Line Therapy for Advanced Renal Cell Carcinoma: A Retrospective Claims Analysis

TABLE 2 Persistence and Compliance Outcomes in Postmatch Population (6-Month Follow-up) ${ }^{\mathrm{a}}$

\begin{tabular}{|c|c|c|c|}
\hline \multirow{3}{*}{ Discontinuation, $\mathbf{n}(\%)$} & \multirow{2}{*}{$\begin{array}{c}\text { Pazopanib } \\
(\mathrm{N}=84)\end{array}$} & \multirow{2}{*}{$\begin{array}{c}\text { Sunitinib } \\
(\mathrm{N}=84)\end{array}$} & \multirow{3}{*}{$\frac{P \text { Value }}{0.732}$} \\
\hline & & & \\
\hline & $(46.4)$ & $(44.1)$ & \\
\hline Persistence with index therapy, mean (SD [median]) & $133.4(62.8[184.0])$ & $139.9(55.6[184.0])$ & 0.445 \\
\hline \multicolumn{4}{|l|}{ Estimated level of persistence with index therapy, $\mathbf{n}(\%)$} \\
\hline 30 days & $(96.4)$ & $(100.0)$ & - \\
\hline 60 days & $(84.5)$ & $(84.5)$ & 1.000 \\
\hline 90 days & $(71.4)$ & $(72.6)$ & 0.862 \\
\hline 120 days & $(65.5)$ & $(67.9)$ & 0.715 \\
\hline 180 days & $(53.6)$ & $(56.0)$ & 0.732 \\
\hline \multicolumn{4}{|l|}{ Proportion of days covered } \\
\hline Continuous value, mean (SD [median]) & $0.68(0.31[0.82])$ & $0.77(0.25[0.90])$ & 0.037 \\
\hline$\geq 80 \%, \mathrm{n}(\%)$ & $(52.4)$ & $(56.0)$ & 0.622 \\
\hline \multicolumn{4}{|l|}{ Medication possession ratio ${ }^{b}$} \\
\hline Continuous value, mean (SD [median]) & $0.90(0.12[0.94])$ & $0.95(0.08$ [0.99]) & 0.008 \\
\hline$\geq 80 \%, \mathrm{n}(\%)$ & $(81.4)$ & $(93.2)$ & 0.118 \\
\hline \multicolumn{4}{|c|}{$\begin{array}{l}{ }^{a} \text { For the matched population, we used the McNemar test to test differences in categorical data and the paired t-test for continuous data. If discordant pairs were <20, we } \\
\text { used the exact McNemar test for categorical data testing. } \\
{ }^{b} N=59 \text { for number of pairs with at least } 2 \text { index drug fills to calculate medication possession ratio. } \\
S D=\text { standard deviation. }\end{array}$} \\
\hline
\end{tabular}

first-line therapy for advanced RCC, less is known about patient compliance and persistence with these drugs in clinical practice.

Wide-ranging median durations of treatment have been observed in retrospective studies of oral RCC treatments: 4-7 months for pazopanib, ${ }^{15,20}$ 3-11 months for sunitinib, ${ }^{31-34}$ 4-8 months for sorafenib, ${ }^{32-35}$ and 8-10 months for bevacizumab. ${ }^{34,35}$ In the clinical trial that demonstrated pazopanib was noninferior to sunitinib with regard to PFS, the median duration of exposure to the study drugs was 8 months for pazopanib and 8 months for sunitinib. ${ }^{36}$ Factors influencing duration of treatment have not been consistently studied. However, retrospective chart review ${ }^{33,35}$ and claims database studies ${ }^{31,32}$ have shown that a high proportion (15\%-40\%) of patients will discontinue, reduce dosage, or switch oral RCC treatments due to adverse events. Thus, studies of compliance and persistence patterns are vitally important.

To date, no other study has retrospectively compared compliance and persistence between pazopanib and sunitinib as first-line therapies using claims data. However, some studies have generated data we can use to compare some measures. For example, Hackshaw et al. (2014) studied pazopanib using claims data among treatment-naive (first-line of therapy) patients and those with prior therapy $\left(2+\right.$ lines). ${ }^{20}$ In that study, which used similar methods and outcomes measures as the current study, the estimated level of persistence with pazopanib at 90 days was 56\% in the treatment-naive cohort and 58\% among those with prior therapy. In the current study, estimated level of persistence with treatment was much higher at 60 days and slightly higher at 90 days. At 60 days, we found $85 \%$ of patients were persistent with treatment for both drugs, yet in another claims database study of first-line sunitinib, 63\% of patients were persistent at 60 days. ${ }^{32}$ Another retrospective claims study showed $71 \%$ were persistent with sunitinib at 6 months, as compared with $56 \%$ in our study. ${ }^{31}$ In the current study, there were no significant differences between cohorts at any time between 30 and 180 days, with approximately 60\% at 90 days and greater than $50 \%$ at 180 days. However, differences in populations, methods, and definitions of outcomes measures hinder exact comparisons between studies. Ours is the first study to demonstrate that persistence and compliance is similar between the 2 drugs at the first-line stage of treatment in a real-world setting, as determined by health care claims. This information may influence determination of choice of medication, although neither effectiveness nor side effects were reported in this study.

In the current study, mean (SD) time to discontinuation was 133 (63) days and 140 (56) days among pazopanib and sunitinib cohorts, respectively. In the Hackshaw et al. study, the mean (SD) number of days to discontinuation of pazopanib was 112 (63) days in the first-line cohort and 119 (61) days in the $2+$ line cohort. ${ }^{20}$ In the study by Hess et al. (2013), ${ }^{31}$ mean duration of therapy on sunitinib was 144 days, and the Filson et al. study (2011) did not report mean duration of therapy. ${ }^{32}$ Although using a different source population, our study reports similar days to discontinuation as found in the few prior comparable studies using different populations.

In the study of pazopanib by Hackshaw et al., high (> 80\%) persistence (PDC) and high (> 80\%) compliance (MPR) were found in both the first-line treated (65\% of patients with high persistence and $67 \%$ with high compliance) and the $2+$ line 


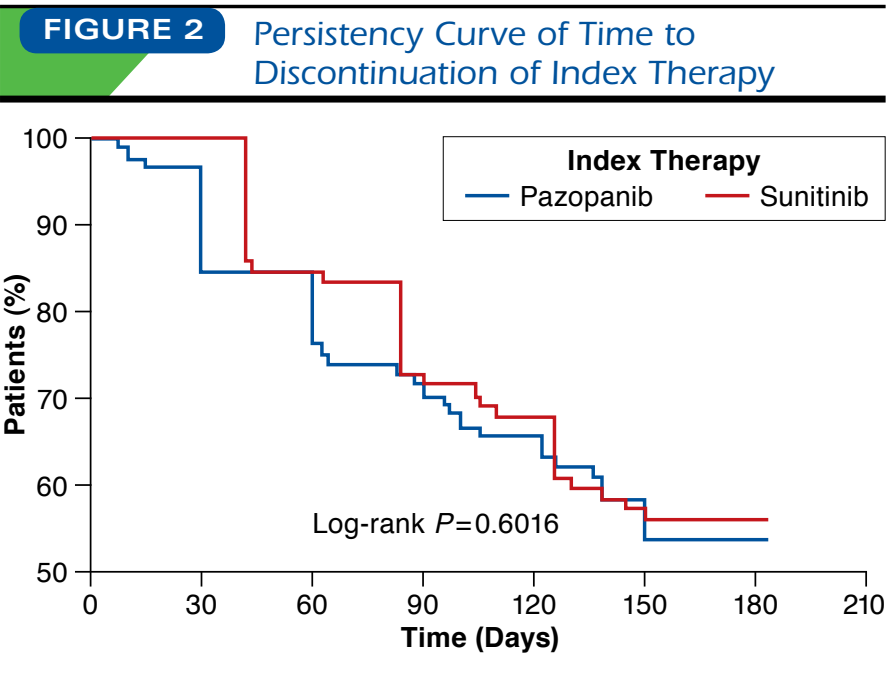

cohort ( $80 \%$ and $83 \%$, respectively) ${ }^{20}$ In the current study, the same definitions of high (>80\%) persistence and high (> 80\%) compliance were used, with no significant differences between drugs: $52 \%$ of patients in the pazopanib cohort and 56\% of patients in the sunitinib cohort were identified as having high persistence, as measured by PDC. High compliance was found among $81 \%$ of patients receiving pazopanib and $93 \%$ of patients receiving sunitinib, as measured by MPR. However, mean PDC and mean MPR were higher for sunitinib.

In summary, no differences were found in percentages of patients with high persistence and high compliance with pazopanib and sunitinib in the first 6 months after therapy initiation. Greater than $50 \%$ of patients in both drug cohorts were persistent with their index therapies at the end of the 6-month observation period. Although persistence and compliance were high, there was a nontrivial proportion of patients ( $40 \%)$ with low persistence. This finding demonstrates the importance of better understanding the reasons for early discontinuation in the real-world setting.

\section{Limitations}

Certain limitations affect the interpretation of results using health insurance claims data. First, the data may be subject to coding errors and incomplete claims history, although the extent of either factor should be equally distributed between cohorts. The prescription fill data provided do not verify actual administration or ingestion of the drug as prescribed and does not account for the possibility that patients acquired prescription medications from nonpharmacy sources. However, by using a variety of measures of persistence, we are confident in our ability to detect differences where they existed. Care received within a clinical trial may not generate claims for some services; these would not be included in analyses, and the degree to which this would influence our measured outcomes is unknown.
Even though propensity score matching was used to balance study cohorts, some selection bias may exist due to characteristics not captured in claims. The available follow-up period was short (184 days) and may not be long enough to observe all clinically relevant differences in the outcomes examined. Future studies should include a longer follow-up period. Finally, data included in this study are from commercially insured and Medicare Advantage-insured populations and may not be generalizable to other populations (e.g., Medicaid or uninsured).

\section{Conclusions}

In this study, there were no significant differences in time to discontinuation for the pazopanib and sunitinib cohorts, and more than one-half of patients in both cohorts were persistent with their index drugs 6 months after initiation. In addition, the percentage of patients with high $(\geq 80 \%)$ PDC (a measure of persistence) and high MPR (a measure of compliance) were similar across drug cohorts, although mean PDC and mean MPR were higher among the sunitinib cohort. Future studies should examine persistence and compliance for both drugs with larger cohorts and a longer follow-up period.

\section{Authors}

STACEY A. DACOSTA BYFIELD, PhD, MPH, is Director, and JEFFREY T. MCPHEETERS, BA, is Senior Analyst, Health Economics and Outcomes Research, Optum, Eden Prairie, Minnesota. TANYA M. BURTON, PhD, is Associate Director, Optum, Waltham, Massachusetts. SAURABH P. NAGAR, BPharm, MS, is Manager, Value Evidence Analytics, GlaxoSmithKline, Durham, North Carolina, and MICHELLE D. HACKSHAW, BScPharm, MSHS, PhD, is Director, U.S. Health Outcomes Oncology, GlaxoSmithKline, Philadelphia, Pennsylvania.

AUTHOR CORRESPONDENCE: Stacey A. DaCosta Byfield, PhD, MPH, Director, Health Economics and Outcomes Research, Optum, MN002-0258, 12125 Technology Dr., Eden Prairie, MN 55344. Tel.: 952.833.6491; Fax: 952.833.6045;

E-mail: stacey.dacostabyfield@optum.com.

\section{DISCLOSURES}

This study was funded by GlaxoSmithKline (GSK). Hackshaw and Nagar are employees of, and hold stock in, GSK. DaCosta Byfield, McPheeters, and Burton are employees of Optum, which received consulting fees for research relating to this study. However, employment at Optum is not dependent on study fees from GSK. Medical writing support was provided by Optum with funding by GSK.

The manuscript for this article was accepted as an abstract only at the 50th annual meeting of the American Society of Clinical Oncology, Chicago, Illinois. An abstract outlining an earlier version of these study results was published in the Journal of Clinical Oncology, volume 32, 2014 supplement edition (abstract e17646) 
Study concept and design were contributed by DeCosta Byfield, Burton, Hackshaw, McPheeter, and Nagar. Data collection was carried out primarily by McPheeter, along with DaCosta Byfield and Burton, with assistance from Nagar and Hackshaw. DaCosta Byfield, Nagar, Hackshaw, and McPheeter were responsible for data interpretation, with assistance from Burton. The manuscript was written by DaCosta Byfield, Burton, and Hackshaw, assisted by McPheeter and Nagar, and revised by McPheeter, Hackshaw, DaCosta Byfield, Burton, and Nagar.

\section{REFERENCES}

1. Siegel RL, Miller KD, Jemal A. Cancer statistics, 2015. CA Cancer J Clin. 2015;65(1):5-29.

2. American Cancer Society. Kidney cancer (adult)—renal cell carcinoma overview. Available at: http://www.cancer.org/acs/groups/cid/documents/ webcontent/003052-pdf.pdf. Accessed April 20, 2015.

3. American Cancer Society. Cancer facts \& figures, 2014. Available at: http://www.cancer.org/research/cancerfactsstatistics/cancerfactsfigures2014/ index. Accessed April 20, 2015.

4. Gupta K, Miller JD, Li JZ, Russell MW, Charbonneau C. Epidemiologic and socioeconomic burden of metastatic renal cell carcinoma (mRCC): a literature review. Cancer Treat Rev. 2008;34(3):193-205.

5. Motzer RJ, Bacik J, Schwartz LH, et al. Prognostic factors for survival in previously treated patients with metastatic renal cell carcinoma. J Clin Oncol. 2004;22(3):454-63

6. Sun M, Thuret R, Abdollah F, et al. Age-adjusted incidence, mortality, and survival rates of stage-specific renal cell carcinoma in North America a trend analysis. Eur Urol. 2011;59(1):135-41.

7. Motzer RJ, Russo P. Systemic therapy for renal cell carcinoma. J Urol. 2000;163(2):408-17.

8. Coppin C, Porzsolt F, Awa A, Kumpf J, Coldman A, Wilt T. Immunotherapy for advanced renal cell cancer. Cochrane Database Syst Rev. 2005(1):CD001425.

9. Chowdhury S, Larkin JM, Gore ME. Recent advances in the treatment of renal cell carcinoma and the role of targeted therapies. Eur J Cancer. 2008;44(15):2152-161.

10. Motzer RJ, Agarwal N, Beard C, et al. Kidney cancer. J Natl Compr Canc Netw. 2011;9(9):960-77.

11. Singer EA, Gupta GN, Srinivasan R. Targeted therapeutic strategies for the management of renal cell carcinoma. Curr Opin Oncol. 2012;24(3):284-90.

12. VOTRIENT (pazopanib) tablets. GlaxoSmithKline. Revised April 2012. Available at: http://www.accessdata.fda.gov/drugsatfda_docs/ label/2012/022465s-010S-012lbl.pdf. Accessed April 20, 2015.

13. SUTENT (sunitinib malate) capsules, oral. Pfizer Labs. Revised May 2011. Available at: http://www.accessdata.fda.gov/drugsatfda_docs/ label/2011/021938s13s17s18lbl.pdf. Accessed April 20, 2015.

14. Motzer RJ, Jonasch E, Agarwal N, et al. Kidney cancer, version 2. 2014. J Natl Compr Canc Netw. 2014;12(2):175-82.

15. Sternberg CN, Davis ID, Mardiak J, et al. Pazopanib in locally advanced or metastatic renal cell carcinoma: results of a randomized phase III trial. J Clin Oncol. 2010;28(6):1061-68.

16. Motzer RJ, Hutson TE, Tomczak P, et al. Sunitinib versus interferon alfa in metastatic renal-cell carcinoma. N Engl J Med. 2007;356(2):115-24.

17. Motzer RJ, Hutson TE, Cella D, et al. Pazopanib versus sunitinib in metastatic renal-cell carcinoma. N Engl J Med. 2013;369(8):722-31.
18. Halpern R, Becker L, Iqbal SU, Kazis LE, Macarios D, Badamgarav E. The association of adherence to osteoporosis therapies with fracture, all-cause medical costs, and all-cause hospitalizations: a retrospective claims analysis of female health plan enrollees with osteoporosis. J Manag Care Pharm. 2011;17(1):25-39. Available at: http://www.amcp.org/data/jmcp/25-39.pdf.

19. Stanford RH, Buikema AR, Riedel AA, Camargo CA Jr, Rey GG, Chapman KR. Asthma controller delay and recurrence risk after an emergency department visit or hospitalization. Respir Med. 2012;106(12):1631-38.

20. Hackshaw MD, Nagar SP, Parks DC, Miller LA. Persistence and compliance with pazopanib in patients with advanced renal cell carcinoma within a U.S. administrative claims database. J Manag Care Spec Pharm. 2014;20(6):603-10. Available at: http://www.amcp.org/WorkArea/ DownloadAsset.aspx?id=18156.

21. Quan H, Sundararajan V, Halfon P, et al. Coding algorithms for defining comorbidities in ICD-9-CM and ICD-10 administrative data. Med Care. 2005;43(11):1130-39.

22. Peterson AM, Nau DP, Cramer JA, Benner J, Gwadry-Sridhar F, Nichol M. A checklist for medication compliance and persistence studies using retrospective databases. Value Health. 2007;10(1):3-12.

23. Ho PM, Rumsfeld JS, Masoudi FA, et al. Effect of medication nonadherence on hospitalization and mortality among patients with diabetes mellitus. Arch Intern Med. 2006;166(17):1836-41.

24. Rosenbaum PR, Rubin DB. The central role of the propensity score in observational studies for causal effects. Biometrika. 1983;70(1):41-55.

25. Parsons LS. Reducing bias in a propensity score matched-pair sample using greedy matching techniques. Presented at: 26th Annual Meeting of the SAS Users Group International; April 22-25, 2001; Long Beach, CA.

26. Bedell $\mathrm{CH}$. A changing paradigm for cancer treatment: the advent of new oral chemotherapy agents. Clin J Oncol Nurs. 2003;7(6 Suppl):5-9.

27. Makubate B, Donnan PT, Dewar JA, Thompson AM, McCowan C. Cohort study of adherence to adjuvant endocrine therapy, breast cancer recurrence and mortality. Br J Cancer. 2013;108(7):1515-24.

28. Ruddy K, Mayer E, Partridge A. Patient adherence and persistence with oral anticancer treatment. CA Cancer J Clin. 2009;59(1):56-66.

29. Foulon V, Schoffski P, Wolter P. Patient adherence to oral anticancer drugs: an emerging issue in modern oncology. Acta Clin Belg. 2011;66(2):85-96.

30. Gebbia V, Bellavia G, Ferraù F, Valerio MR. Adherence, compliance and persistence to oral antineoplastic therapy: a review focused on chemotherapeutic and biologic agents. Expert Opin Drug Saf. 2012;11(Suppl 1):S49-59.

31. Hess G, Borker R, Fonseca E. Treatment patterns: targeted therapies indicated for first-line management of metastatic renal cell carcinoma in a real-world setting. Clin Genitourin Cancer. 2013;11(2):161-67.

32. Filson CP, Redman BG, Dunn RL, Miller DC. Initial patterns of care with oral targeted therapies for patients with renal cell carcinoma. Urology. 2011;77(4):825-30.

33. Feinberg BA, Jolly P, Wang ST, et al. Safety and treatment patterns of angiogenesis inhibitors in patients with metastatic renal cell carcinoma: evidence from US community oncology clinics. Med Oncol. 2012;29(2):786-94.

34. Choueiri TK, Duh MS, Clement J, et al. Angiogenesis inhibitor therapies for metastatic renal cell carcinoma: effectiveness, safety and treatment patterns in clinical practice-based on medical chart review. BJU Int. 2010;105(9):1247-54

35. Oh WK, McDermott D, Porta C, et al. Angiogenesis inhibitor therapies for advanced renal cell carcinoma: toxicity and treatment patterns in clinical practice from a global medical chart review. Int J Oncol. 2014;44(1):5-16.

36. Motzer RJ, McCann L, Deen K. Pazopanib versus sunitinib in renal cancer. N Engl J Med. 2013;369(20):1970. 